\title{
A Cover Type Hollow Extrusion Die for The Semi-hollow Al-profiles
}

\author{
Xuemei Huang ${ }^{1, a}{ }^{*}$, RurongDeng ${ }^{2, b^{*}}$ \\ ${ }^{1}$ Guangzhou Vocational College of Science and Technology, Guangzhou, 510550, China \\ ${ }^{2}$ Guangzhou Vocational College of Science and Technology, Guangzhou, 510550, China \\ aemail:41784402@qq.com, bemail:SQF6410@163.com
}

Keywords: aluminum profile,semi-hollow, die structure,cover,design

Abstract:the determination methods of semi-hollow profiles were introduced.A new protective die structure was analyzed.and the selection of design parameters was introduced.the structure has a good effect on improving the strength and the life of the die and the quality of the products was showed that it is a structure worthy of promotion.objective to promote the technology and the die structure to the counterparts,to provide reliable and valid reference.

\section{Introduction}

In the production process of aluminum profile, The die is the key and important factor. In many of the aluminum species, according to their structural characteristics,these profiles can be summed up into two categories, namely hollow aluminum profile and non hollow aluminum. The aluminum profile extrusion die is generally divided into two categories: the hollow type and the solid die. The former is mainly used for the extrusion of hollow sections, the latter is used for the extrusion of solid material.But in practice there is a considerable part of the solid profile that it can not be extruded by a solid die, if using the conventional flat die structure, the strength of the die will be insufficient, computer, to collapse the broken cause premature die failure situation, the service life of the die not up to normal levels.But in practice, there are a considerable part of the solid material is not flat die extrusion, if the use of conventional solid die structure, the die strength will be insufficient, the die will appear collapse, break, etc. so as to take the premature failure of the die, and the die life can not reach normal levels. This type of profiles, known as the "semi - hollow profile" in the industry.The important problem in the design of the semi - hollow profile extrusion die is to solve the strength of the die.In order to solve the problem of the strength of the die, the domestic and foreign experts and technical personnel carry out a wide range of research.In this paper, a new type of semi - hollow profile is introduced, which is based on the practical example, and is used for reference.

\section{The structure of the cover type hollow die}

\section{The profile shown in Figure 1 as an example.}

The tongue ratio of the profile is 0.6, and the minimum width of the cantilever opening is $111.8 \mathrm{~mm}$.If the use of one type of solid die, after the intensity of the calculation, the thickness of the die at least $105 \mathrm{~mm}$, which brings a lot of difficulties to process. With the cover type hollow die, the most of the cantilever can be placed in the center of the hollow die. The majority of the cantilever is covered by the structure which avoids the direct positive pressure when the cantilever is subjected to the layered compression,thereby it can improve the stress state of the cantilever,The effective thickness of the cantilever can be reduced, which is beneficial to the processing of the die. 


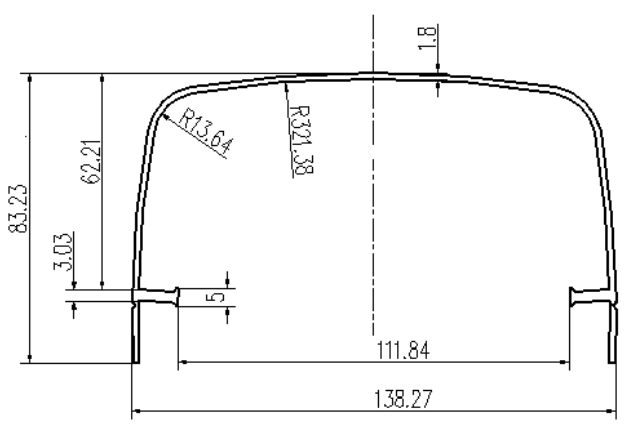

Fig. 1 The signal of profile section

The die structure is shown in figure 2.

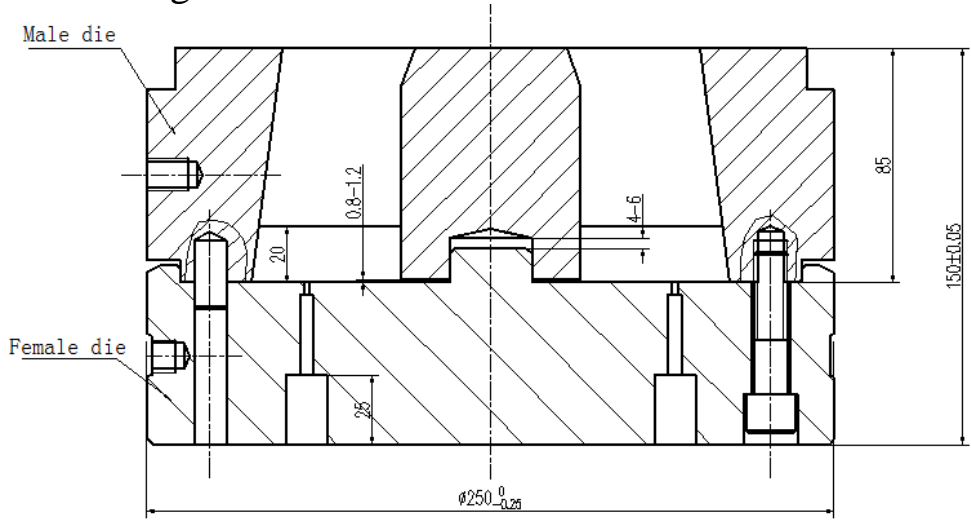

Fig.2 The signal of the die structure

\section{The key points for the design of the cover type hollow die}

(1) the positive pressure in extrusion is mainly borne by the male die. Therefore, the strength of the male die must be ensure .

(2) when the porthole is arranged, it is to be noted that the porthole is not arranged at one end of the cantilever supporting edge (the cantilever root).The area difference of each porthole is controlled at about $10 \%$, and the feeder ratio is $30 \% \sim 40 \%$, which can reduce the extrusion pressure and increase the strength of the die.At the same time, the structure of sink is used in bridge, The equivalent of the male die construction of a welding chamber, welding chamber height is sinking depth of general $20 \mathrm{~mm} \sim 25 \mathrm{~mm}$.In order to reduce the compression area of the upper die, the parallel inclined feed mode can be used,The spreader angle and the feeder angle near the center of the die is consistent, or slightly larger than 1 to 2 degrees, and a chamfer must be made on porthole feeder end.This will effectively reduce the extrusion pressure. The feeder hole and the bridge were shown in Figure 3.

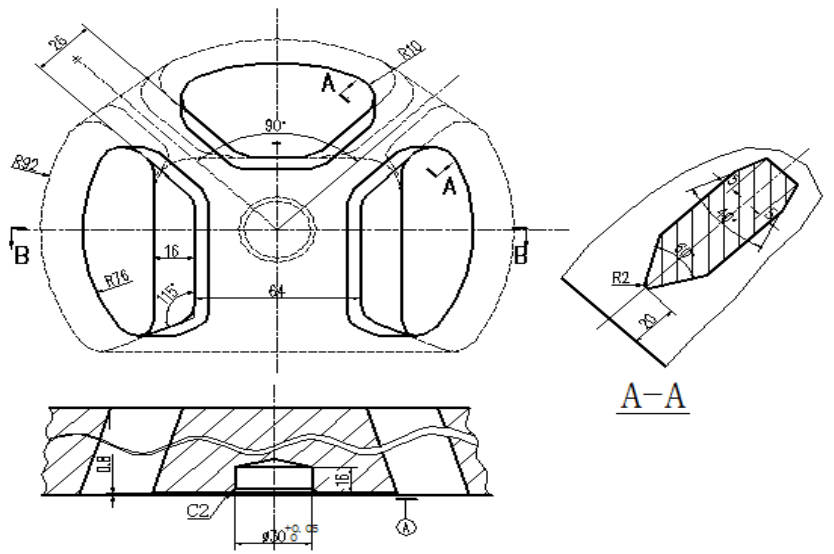

$\underline{B-B}$

Fig.3 The feeder hole and bridge of male die 
(3) With the use of this structure ,the stress gap from 0.5 mmto $1.2 \mathrm{~mm}$ must be designed.But the principle of the minimum gap is not greater than the minimum wall thickness, and the larger the area of the cantilever is, the stress gap should be increased.it must be ensure that the male die in the extrusion process does not transfer the positive pressure to the female die.

(4) Due to the friction of the metal, the elastic deformation of the cantilever will also occur [2], so that the bottom gap becomes smaller.Therefore, in the die design,the elastic reserve to the gap must be considered. Otherwise, the bottom profile wall thickness will be small, but also affect the flow of the metal flow. The gap reservation is general from $0.10 \mathrm{~mm}$ to $0.20 \mathrm{~mm}$.

(5) Because of a sinking structure in the bridge, so it should not be designed a welding chamber in male die, it will simplify the processing mode.But a convex platform with the male die must be designed, and the convex is placed as far as possible at the center of the die, so as to facilitate the processing and ensure the accuracy of the male and female die positioning. The diameter of the boss should not be too small and too high, it should be ensured that the convex sets are rigid enough.Experience indicates, the boss diameter from $12 \mathrm{~mm}$ to $40 \mathrm{~mm}$ is appropriate, height from $8 \mathrm{~mm}$ to $12 \mathrm{~mm}$ is appropriate. The larger area of the cantilever, the boss diameter is bigger.The selection of the bearing is chosen according to the principle of the conventional hollow die.The boss on the female die and the bearing were shown in Figure 4.

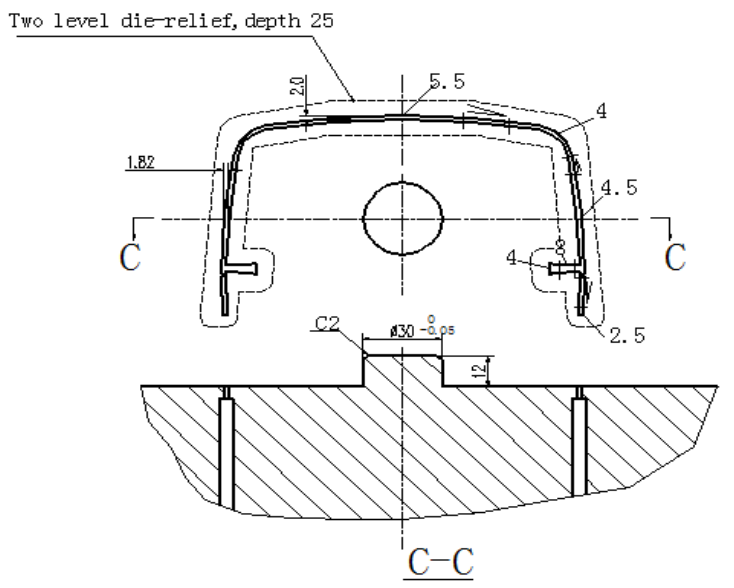

Fig. 4 The boss on the female die and the bearing

Using this structure, it should be set up to the "convex table".The projecting part of the female die cantilever center (so easy processing) or in slightly deviated from the center position at the setting to the positioning lug boss, and the male die in the hollowing out of the position. On the contrary, it is feasible.There is a certain gap between the two part (usually take $0.20 \sim 0.3 \mathrm{~mm}$ ). The convex table is constrained by the male die when the pressure of the inner friction is depressed,It can effectively eliminate the die sinking, so as to reduce the deformation of the cantilever, while improving the stress state of the cantilever.The stress state of the cantilever is equivalent to a simply supported beam by a cantilever beam. The principle is shown in figure 5. Greatly improve the strength of the die.

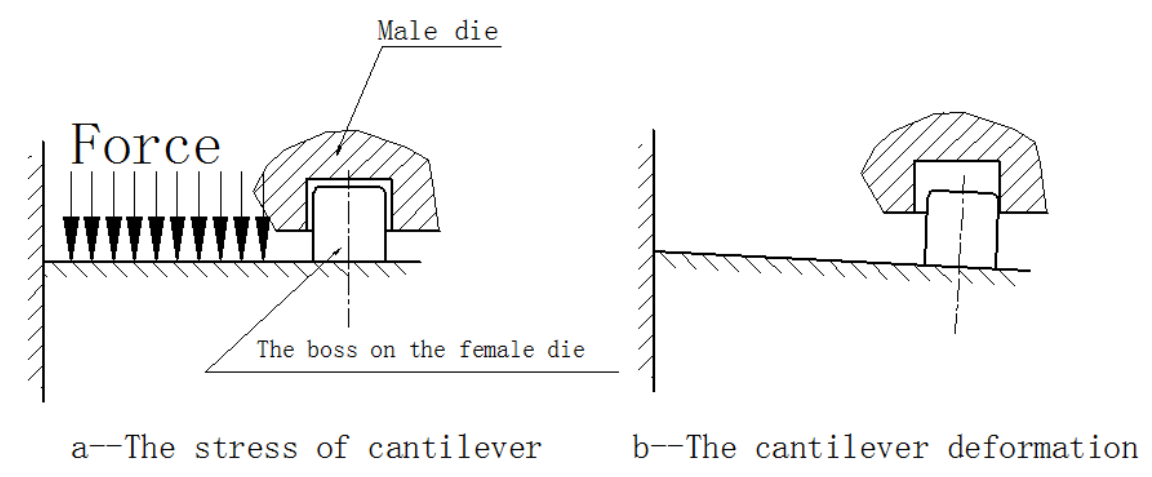

Fig.5 The positioning principle for the tongue

(6) Using the cover type hollow die, The best effect is collocation special die support and die 
backer,Namely so-called "front cover back support" way

\section{Extrusion results contrast}

According to the extrusion tracking for the profile shown in figure 1 using the traditional solid and new cover type of the hollow die structure , the results of the comparison as shown in table 1.

Table1 The comparison of die structure and extrusion results

\begin{tabular}{cccccc}
\hline $\begin{array}{c}\text { Die } \\
\text { structure }\end{array}$ & Die life[ton] & $\begin{array}{c}\text { Wall thickness } \\
\text { deviation[mm] }\end{array}$ & $\begin{array}{c}\text { Surface } \\
\text { quality }\end{array}$ & $\begin{array}{c}\text { Dimension } \\
\text { precision }\end{array}$ & $\begin{array}{c}\text { Cantilever } \\
\text { stress state }\end{array}$ \\
\hline $\begin{array}{c}\text { Traditiona } \\
\text { l solid }\end{array}$ & Less 1 & More than 0.2 & $\begin{array}{c}\text { Extrusion } \\
\text { marks deep, } \\
\text { rough surface }\end{array}$ & $\begin{array}{c}\text { The opening is } \\
\text { small, and the } \\
\text { end face wall } \\
\text { is thin and } \\
\text { serious. }\end{array}$ & $\begin{array}{c}\text { All under } \\
\text { normal } \\
\text { pressure }\end{array}$ \\
$\begin{array}{c}\text { cover type } \\
\text { of the } \\
\text { hollow die }\end{array}$ & More than 10 & No & $\begin{array}{c}\text { Extrusion } \\
\text { marks light, } \\
\text { light surface }\end{array}$ & $\begin{array}{c}\text { High,Meet } \\
\text { technical } \\
\text { requirements }\end{array}$ & $\begin{array}{c}\text { Stress can be } \\
\text { reduced by } \\
\text { more than } \\
80 \%\end{array}$ \\
\hline
\end{tabular}

As can be seen from the results, the new cover type of the hollow die has obvious advantages, greatly improving the service life of the mold, reducing the profile extrusion die cost.

\section{Conclusions}

Extrusion die structure with covered type hollow die, It is to improve the stress state of the cantilever and reduce the force of the metal to the cantilever, so as to improve the rigidity and strength of the die.Using this kind of structure to make full use of the characteristics of metal flow in the extrusion process, the design parameters can be adjusted and arranged, it can achieve a better effect, and it is more advantageous to improve the strength of the mold, prolong the service life and reduce the cost.

\section{References}

[1]Ru-rong Deng, Lei Zeng. The design of flow-guided die in large solid section [J],Light alloy fabrication technology, 2014(11): 29 31 In Chinese

[2]Jian-xin Xie , Jing-an Liu.Metal extrusion theory and technology[M].Metallurgical Industry Press, Beijing, 2001: 28〜31, 68〜69 In Chinese

[3]Zu-tang Wang,Xin-quan Zhang. Research on the design technology of the flow guided die for aluminum profile extrusion die[J],Light alloy fabrication technology,1992(01): 38 42In Chinese

[4]Jing-an Liu. Aluminum alloy extrusion die design,use and maintenance.[M],Metallurgical Industry Press, Beijing,1999:159 167 In Chinese

[5]Ru-rong Deng.To determine the key parameters of aluminum extrusion die design by shunt[J],Light alloy fabrication technology,2002,30(2) : 23 24 In Chinese

[6]Guang Wang,Jian Liu.Technology study of coarse grain ring of 2024 aluminum alloy extrusion bar[J],Light alloy fabrication technology,2013(04): 36 40 In Chinese

[7]Ke-Wei Zhang,Lei Zhang.Effect of pre-stretching on microstructure and mechanical properties of 2A12 aluminum alloy bar[J],Light alloy fabrication technology,2013(11): 37 40 In Chinese

[8]Guang-Lei Lin.Study on the production process of 7A04-T6 aluminum alloy rod[J],Light alloy fabrication technology,2007(11): 33 36 In Chinese 